\title{
Transapical NeoChord mitral valve repair
}

\author{
Andrea Colli ${ }^{1 \#}$, David Adams ${ }^{2}$, Alessandro Fiocco ${ }^{1}$, Nicola Pradegan ${ }^{1}$, Lorenzo Longinotti ${ }^{1}$, Matteo \\ Nadali ${ }^{1}$, Dimosthenis Pandis ${ }^{2 \#}$, Gino Gerosa ${ }^{1}$ \\ ${ }^{1}$ Department of Cardiology, Thoracic and Vascular Sciences, University of Padua, Padua, Italy; ${ }^{2}$ Department of Cardiovascular Surgery, Icahn School \\ of Medicine at Mount Sinai, New York, NY, USA \\ \#These authors contributed equally to this work. \\ Correspondence to: Andrea Colli, MD, PhD, FECTS. Department of Cardiology, Thoracic and Vascular Sciences, University of Padua, via Giustiniani 2, \\ 35128 Padova, Italy. Email: colli.andrea.bcn@gmail.com.
}

\begin{abstract}
Transapical off-pump mitral valve repair (MVr) with NeoChord implantation has become widely applied in Europe for patients presenting with severe mitral regurgitation due to leaflet prolapse or flail. The procedure is performed under real-time 2D- and 3D-transesophageal echocardiography (TEE) for both implantation and neochordae tension adjustment allowing real-time monitoring of hemodynamic recovery. Preoperative anatomic and echocardiographic selection criteria, procedure refinement, as well as innovative ex-vivo surgical simulator training have been developed and strategically employed in the past few years, to generate a robust precision-based procedural framework with significantly enhanced operator use, patient safety and clinical outcomes. The procedure has evolved into a reproducibly successful and safe approach, which complements existing surgical treatment strategies available to eligible patients with chronic severe degenerative mitral regurgitation.
\end{abstract}

Keywords: Mitral regurgitation; mitral insufficiency; mitral valve prolapse; mitral valve flail; mitral valve repair (MVr); NeoChord

Submitted Oct 05, 2018. Accepted for publication Oct 23, 2018.

doi: $10.21037 /$ acs.2018.11.04

View this article at: http://dx.doi.org/10.21037/acs.2018.11.04

\section{Introduction}

Surgical mitral valve repair $(\mathrm{MVr})$ is considered the gold standard treatment for chronic severe degenerative mitral regurgitation (1). The use of expanded polytetrafluoroethylene (e-PTFE) sutures as artificial neochordae to resuspend the prolapsed or flail leaflet margin is a routinely performed technique used in conventional $\mathrm{MVr}$ repair strategies (2). Transcatheter $\mathrm{MVr}$ technologies have lately emerged to offer an alternative option to conventional direct-access approaches for the treatment of high-risk surgical patients. Currently, the use of catheter-based $\mathrm{MVr}$ therapies has expanded to include low- and medium-risk patient groups with promising results (3). The NeoChord Artificial Chordae Delivery System (NeoChord, Inc., St. Louis Park, MN, USA) allows placement of e-PTFE sutures as replacement neochordae on a beating heart without the need for cardiopulmonary bypass $(\mathrm{CPB})$, while using 2D- and 3D-transesophageal echocardiography (TEE) guidance (3-8).

\section{Operative techniques}

\section{Preparation}

The NeoChord transcatheter mitral repair procedure is performed in a standard cardiac operating theatre suite. Optimal 2D- and 3D-TEE imaging units are mandatory for procedural navigation and real-time assessment of mitral regurgitation. The patient is placed under general anesthesia with single-lung ventilation, and positioned supine with a 30-degree right lateral rotation of the thorax to facilitate posterolateral left ventricular (LV) access. Heparin is given at a dose of $100 \mathrm{U} / \mathrm{kg}$ to achieve an activated clotting time of $>300$ seconds. A perfusionist with a primed CPB circuit is always present in the room on stand-by. The femoral artery and 


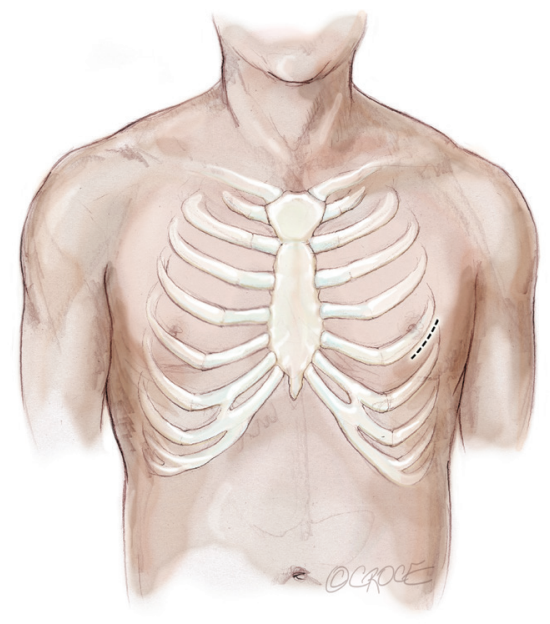

Figure 1 Left anterolateral minithoracotomy in the 5 th intercostal space.

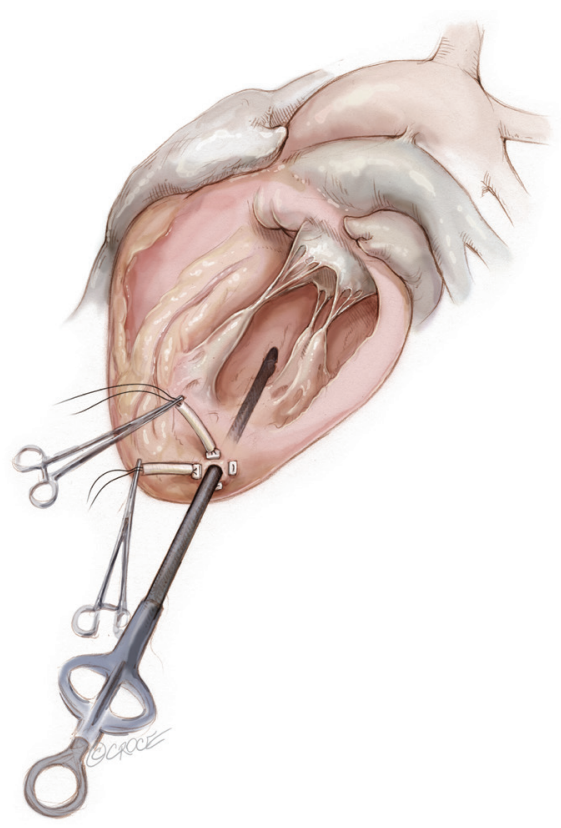

Figure 2 Posterolateral $L V$ access is prepared with two circumferential purse strings reinforced by pledgets. Ventriculotomy is performed and the device is introduced. $\mathrm{LV}$, left ventricular.

vein are prepared for cannulation with a Seldinger catheter wire in situ should the need for $\mathrm{CPB}$ cannulation arise.

\section{Exposure}

A standard left lateral mini-thoracotomy is performed at the fifth intercostal space to access the LV apex (Figure 1). Selective left lung exclusion can be a useful maneuver to improve access to the posterolateral wall of the LV. Pericardial stitches and an intra-pericardial soft tissue retractor are placed to improve exposure and reduce the risk of traction injury. The $L V$ access site is confirmed by $2 \mathrm{D}$-TEE imaging using gentle digital palpation approximately two to three centimeters lateral from the true LV apex. Additionally, identification of the last diagonal coronary artery branch is a useful reference landmark. Simultaneous multi-plane or 'X-plane' imaging is obtained from the mid-esophageal long-axis (ME LAX) and mitral commissural (MC) views. Correct localization of the ideal entry site allows the surgeon to safely navigate the NeoChord device toward the mitral valve while maintaining a correct alignment between the papillary muscles without interfering with the native subvalvular apparatus (5-9).

\section{Operation}

Two concentric, round purse-string sutures with opposite closure points are placed using large custom-made, rectangular Teflon pledgets and 2-0 non-absorbable suture. A transapical ventriculotomy is performed with an 11-blade scalpel incision and then slightly dilated with a long straight clamp. Alternatively, a Seldinger technique with progressive dilators can be used to access the LV. Once the NeoChord device enters the LV cavity, the apical purse-strings are gently tightened to minimize blood leakage and facilitate device insertion (Figure 2).

The NeoChord device is directed towards the mitral valve plane using 2D-TEE guidance (X-plane with ME LAX and MC views) avoiding interference with adjacent subvalvular structures. During 2D-TEE guidance, use of the posterior mitral leaflet as a reference point to generate the corresponding bi-planar view is recommended (Figure 3). When using echocardiographic guidance to navigate and maneuver the NeoChord device, the surgeon should always be aware that the lateral and medial movements of the device seen on imaging are always 'opposite' to the actual physical movements of the device. Most importantly, movement of the NeoChord device must always be performed in the native chordae-free zone of the LV, which is below the level of the papillary muscle tips. It is not recommended to perform any anteroposterior or mediolateral translations of the device in the proximity of the annular plane of the mitral valve (Figure 4).

Progression from the $\mathrm{LV}$ toward the $\mathrm{MV}$ is performed 
by advancing the NeoChord device into the thorax perpendicular to the dome of the posterior leaflet and $\mathrm{MV}$ annular plane (Figure 5). Simultaneous X-plane visualization of the NeoChord device tip is essential during navigation inside the LV cavity (Figures 6-8). While in the LV cavity, once the device tip has reached the posterior mitral leaflet, the surgeon should gently advance the device while

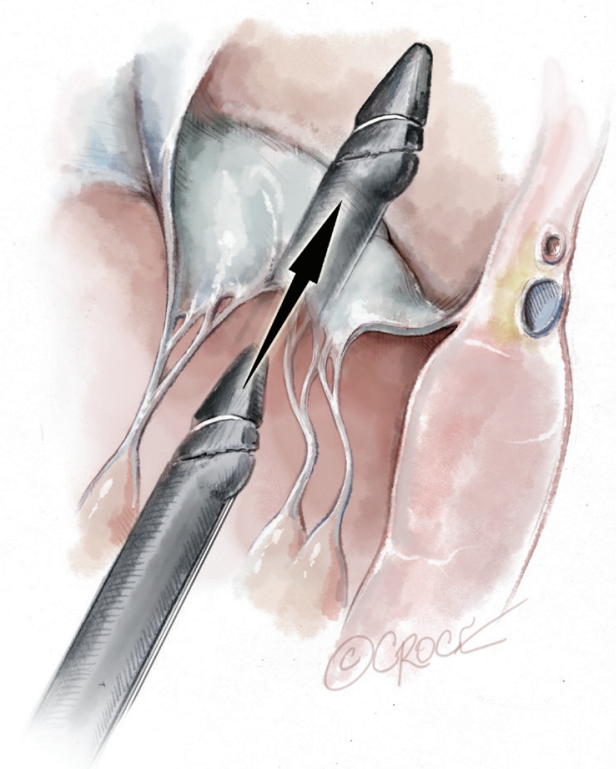

Figure 3 The NeoChord device crosses the mitral valve under 2D transesophageal echocardiographic guidance. simultaneously lowering the tail (or end) of the device, which will allow the tip to slide over the anterior leaflet surface plane and facilitate device advancement across the $\mathrm{MV}$ annular plane and into the left atrium.

Once the MV annular plane has been crossed, the TEE imaging mode should be switched from 2D to full 3D imaging, using a surgical or en face view of the mitral valve to demonstrate the tip of the device and to visualize movement of the device tip towards the target mitral leaflet segment. Presence of any device resistance or the appearance of any unnatural movement of the mitral leaflets during echocardiographic guidance may suggest an unsuccessful device crossing of the annular plane and the maneuver should be aborted and repeated. When an appropriate position has been achieved, the jaws of the NeoChord device are opened and the leaflet edge is gently grasped by withdrawing the device slowly away from the left atrium (Figure 9). Complete, secure leaflet capture is observed when the jaws of the device are closed on the leaflet tissue and all four light indicators on the fiberoptic display monitor turn from red to white (Figure 10).

Once the leaflet capture is confirmed, the surgeon should maintain a firm hold of the instrument and slowly push the device needle forward to advance it through the leaflet segment (Figure 11). Once the needle has been advanced, it is then retracted with a smooth continuous motion to pull the loop of the suture through the leaflet and eventually exit through the proximal tip near the device handle (Figure 12). Once the suture loop has been retrieved from the device,
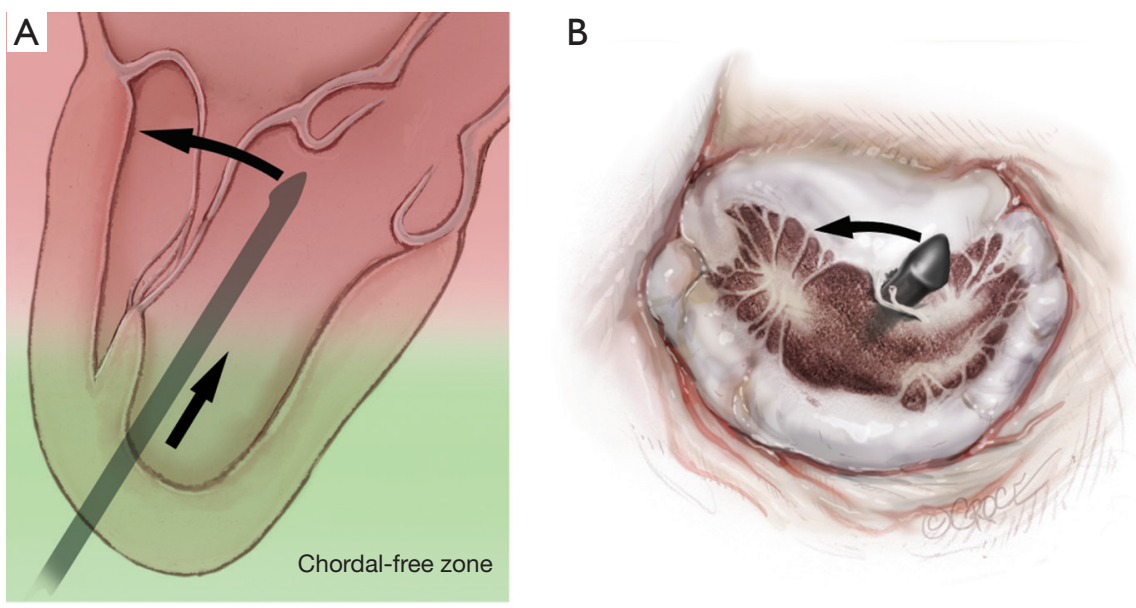

Figure 4 The left ventricle can be divided into two areas, one apical called the chordal free zone limited by the tip of the papillary muscle and one called the chordal area below the leaflet and up to the upper part of the tip of the papillary muscle. The device should be moved anterioposteriorly or mediolaterally only once in the chordal free area in order to avoid entanglement of the subvalvular apparatus. 

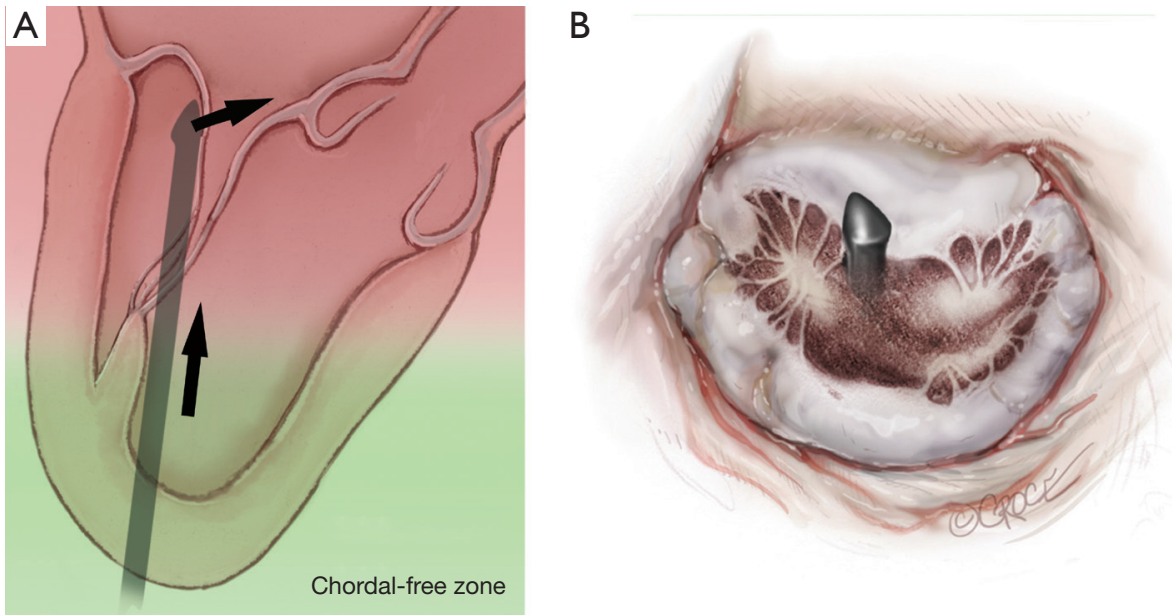

Figure 5 The device tip needs to point toward the dome of the posterior leaflet. Once the dome is reached a gentle downward movement of the handle moves the device tip towards free edge of the posterior leaflet allowing for smooth and safe progression of the device on the atrial surface of the anterior leaflet.
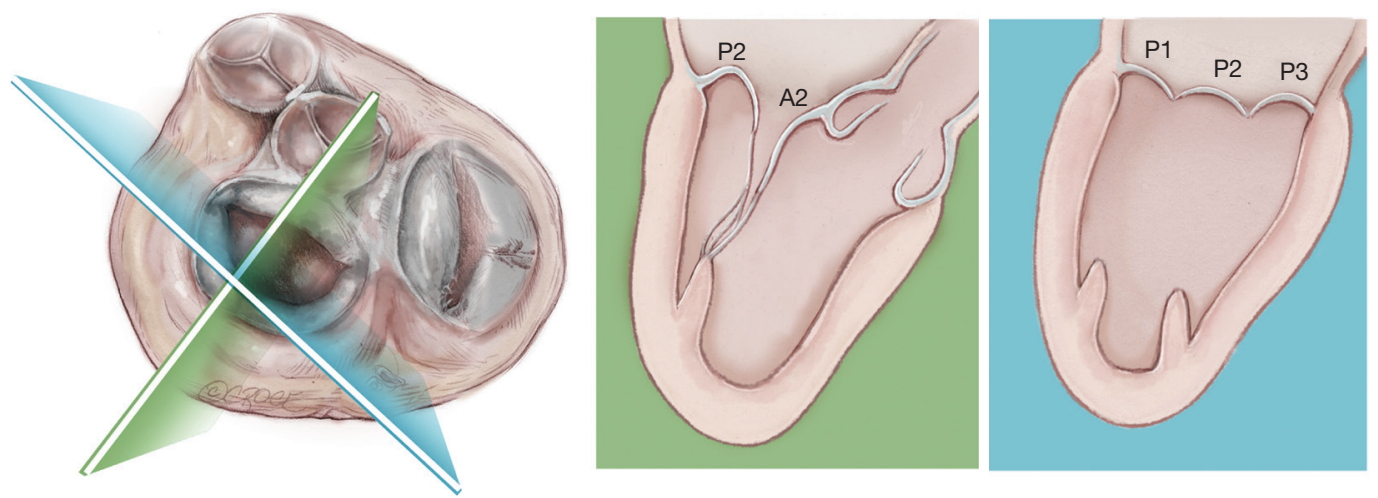

Figure 6 The long axis 3-chamber echocardiographic X-plane view allows visualization from two different angles at $90^{\circ}$. This is the key imaging modality for ventricular navigation and crossing of the mitral valve.
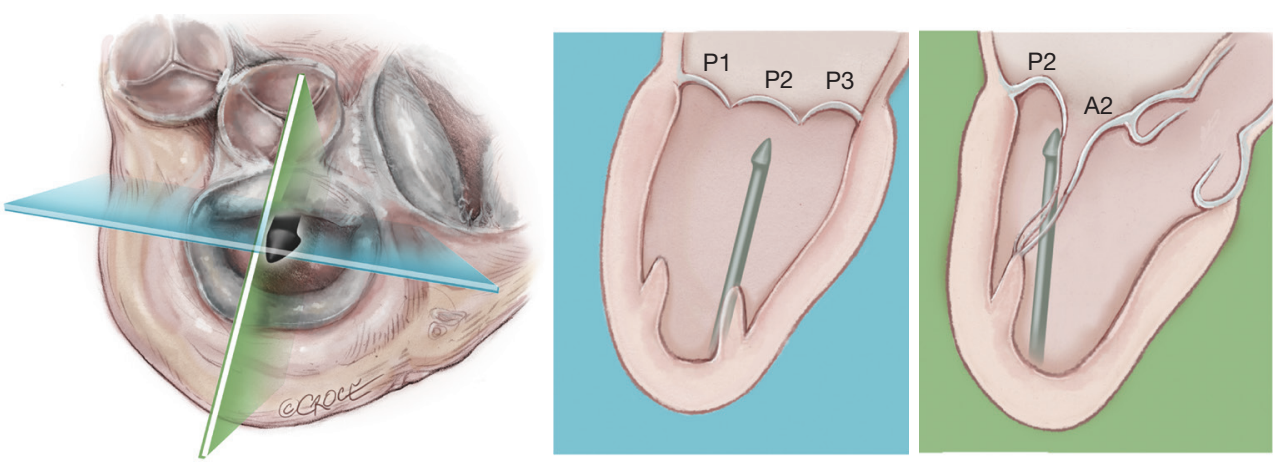

Figure 7 The NeoChord device is simultaneously viewed in both echocardiographic X-plane images allowing for a safe navigation and crossing of the mitral valve in its central area. 

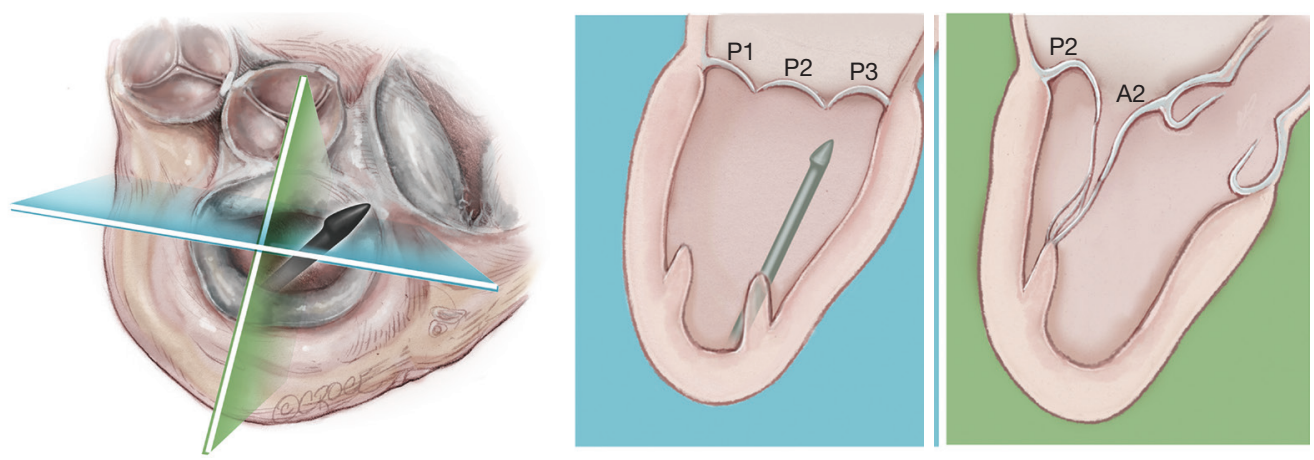

Figure 8 The NeoChord device is seen only in one screen because it is not positioned in the central portion of the mitral valve. Navigation and crossing of the mitral valve present a higher risk of leaflet and chordal damage because of misalignment. It is essential to not lose sight of the device in both echocardiographic images during $L V$ navigation. $L V$, left ventricular.

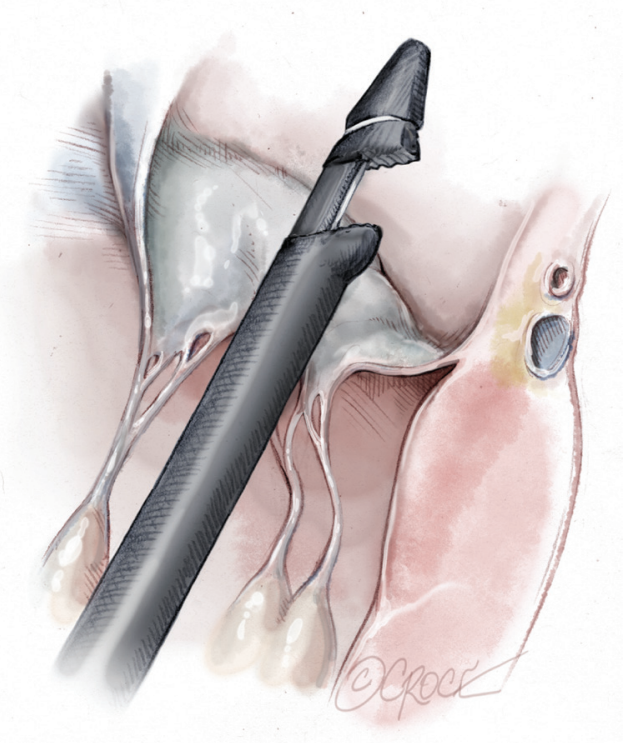

Figure 9 The tip of the NeoChord device is placed over the diseased segment of the mitral leaflet to be treated using $3 \mathrm{D}$ echocardiographic guidance. The jaws of the device are opened.

the apical purse string sutures are loosened and the NeoChord device is retracted from the ventricle with the jaws open (Figure 13). Following retrieval of the device from the $\mathrm{LV}$, the two ends of the suture will be visualized and placed through the suture loop to form a girth hitch knot, which is advanced to the free edge of the captured leaflet while the two ends remain outside the chest for final fixation on the apex (Figures 14,15). Once the retrieval is complete, the apical purse-strings are temporarily re-tightened. The

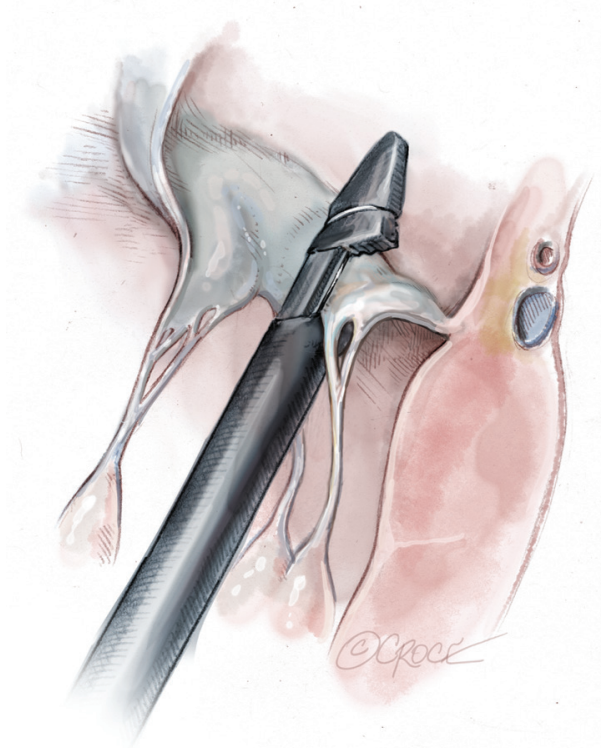

Figure 10 The device is gently retrieved from the left atrium until the point that the inferior jaws load the leaflet. The confirmation monitor shows a lightning flash confirming the correct loading of the leaflet.

device is re-loaded with a new suture and the procedure is repeated until enough neochordae have been implanted to achieve the desired level of valve competence and subsequent reduction in regurgitation (Figure 16).

When the desired number of neochordae have been placed, the apical purse-strings are tied. A French-eye needle is used to pass all the neochordae through a round pledget which is fixed with a 4-0 Prolene suture over the ventriculotomy and tourniquets are placed over each of 


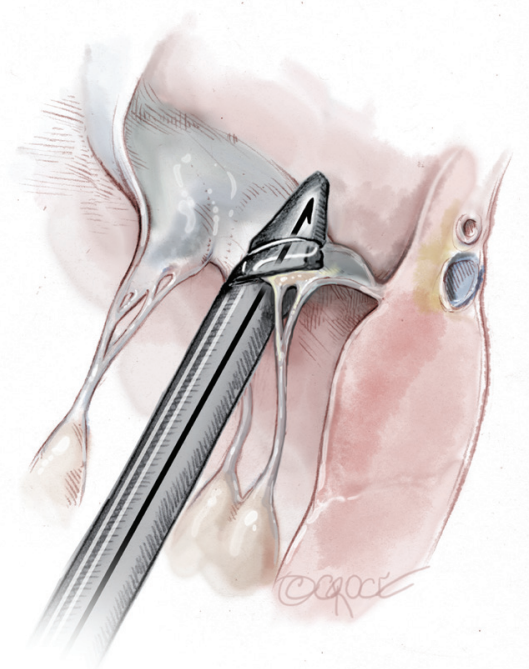

Figure 11 The jaws are closed; the leaflet is punctured and the Gore-Tex chord is passed through.

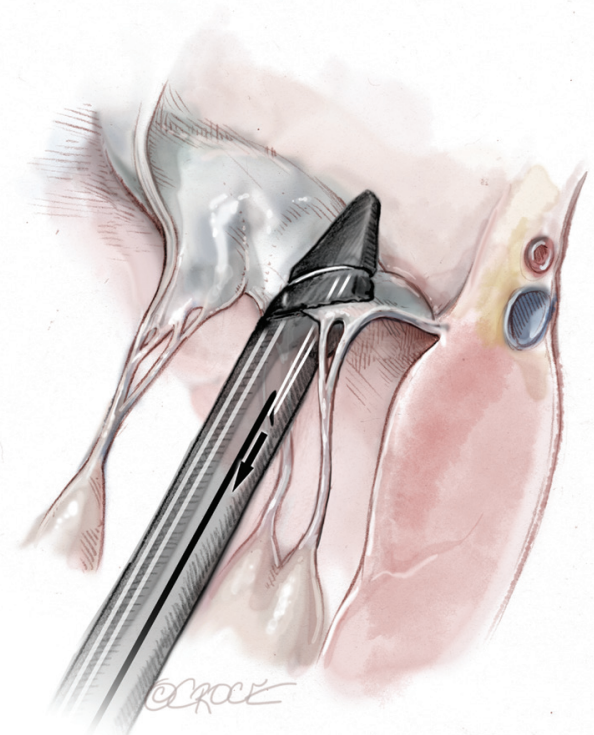

Figure 12 The NeoChord that has been passed is retrieved from the device together with the needle.

the neochordae. The respective length of each NeoChord is then adjusted to achieve optimal leaflet apposition with the lowest degree of mitral regurgitation. In order to establish the desired degree of leaflet coaptation, rightangle atraumatic forceps are placed below each tourniquet

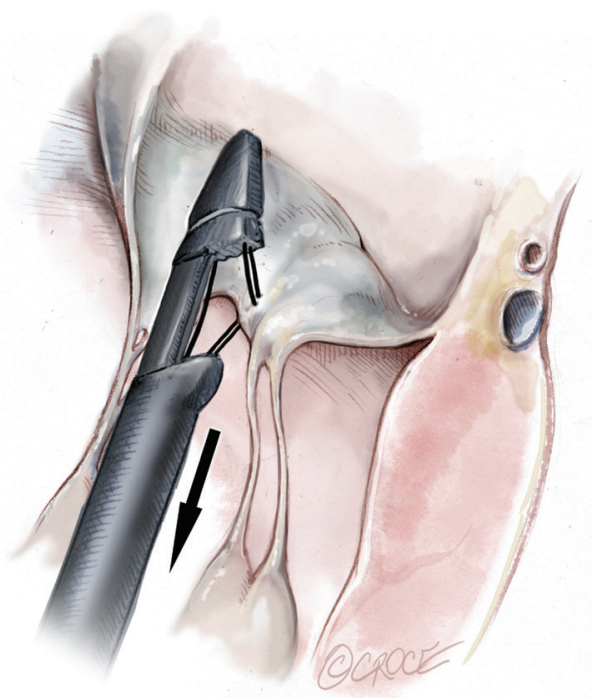

Figure 13 The NeoChord device is opened and retrieved from the left ventricle.

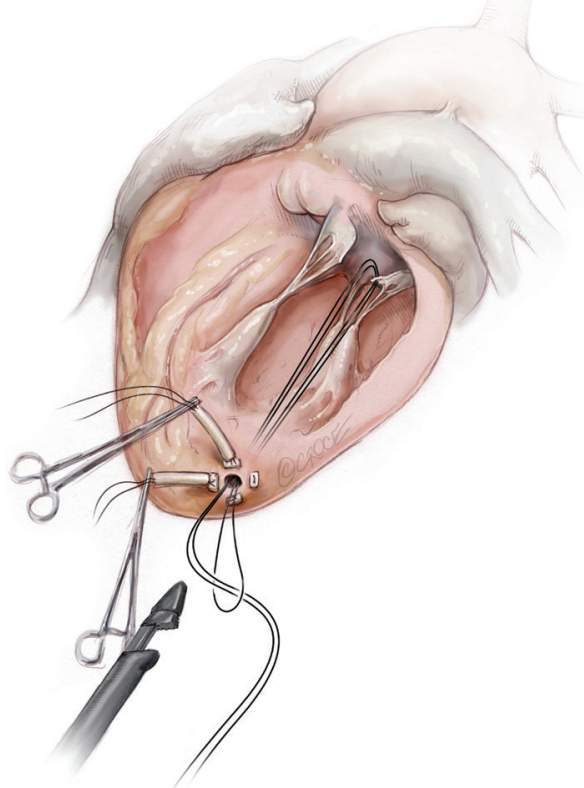

Figure 14 A girth hitch knot is performed.

and secured on each NeoChord. During this process, it is important to ensure over-tension of the artificial chordae to prevent recurrent $M R$ as the major $L V$ axis dimension decreases (apex to base) during reverse remodeling following correction of the MR. Once the length of the 


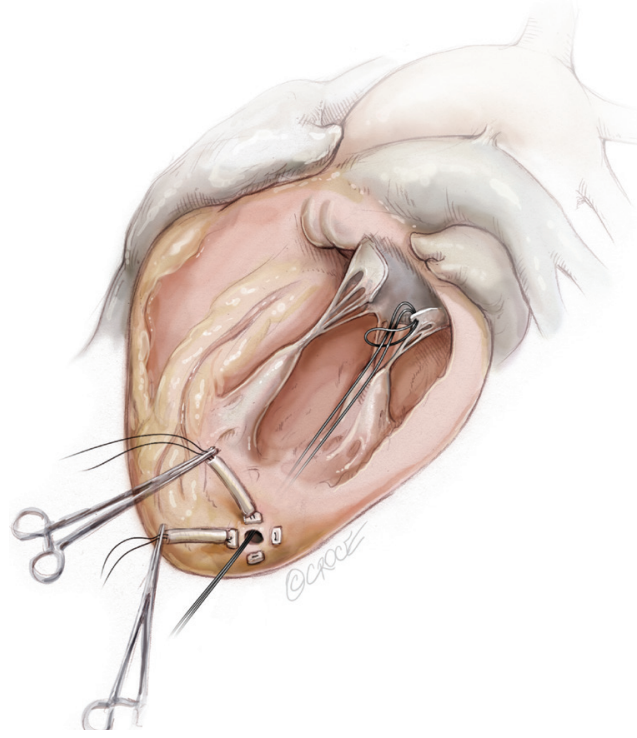

Figure 15 The knot slides in the left ventricle up to the free margin of the treated leaflet fixing the implanted neochord.

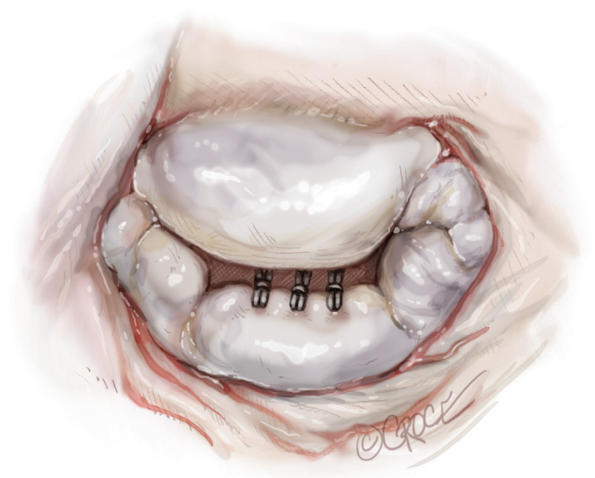

Figure 16 Surgical view of the mitral valve showing three implanted NeoChords on the P2 segment.

neochordae is adjusted, each NeoChord is securely tied to the epicardial pledget. Following partial closure of the pericardium, a pleural drain is inserted and the minithoracotomy is closed in layers, in standard fashion.

\section{Comments}

To date, the NeoChord procedure has been successfully performed in over 1,000 patients in Europe and the USA respectively (unpublished data). Since its first application (10), the NeoChord technology has demonstrated excellent outcomes in reducing mitral regurgitation in eligible patients with chronic severe degenerative mitral regurgitation (4,11-14). In the United States, the NeoChord technology has received investigational device exemption (IDE) approval from the United States Food and Drug Administration (FDA) and subjects are being enrolled in a prospective, multicenter, randomized controlled clinical trial comparing the NeoChord procedure with conventional surgical MV repair (ClinicalTrials.gov NCT02803957). In Europe, a multicenter study recently reported excellent procedural success rates, including $96.7 \%$ of patients demonstrating mild or reduced residual mitral regurgitation postoperatively, $98 \% \pm 1 \%$ one-year survival and freedom from composite endpoints of $84 \% \pm 2.5 \%$ (11). Furthermore, a critical analysis of the procedure-operator performance (quality control) during the 'learning curve' period using cumulative sums charts, showed a sharp decrease in the actual probability of failure to $\leq 10 \%$ after 49 cases performed and to $5 \%$ after $\geq 81$ cases, with use of an acceptable adverse event rate threshold of $5 \%$, well below the $10-15 \%$ rate used in published literature $(15,16)$. This demonstrates a relatively short learning curve required to achieve expertise in performing the NeoChord procedure safely and successfully. These rates, nonetheless, are still subject to continuous improvement mainly due to ongoing procedural improvements and standardization $(12,17)$.

Currently and despite the disciplined selection process based on clear inclusion and exclusion criteria, there is little equipoise in the definition of the ideal candidate for the NeoChord procedure. In our series of patients, we have observed that $\mathrm{MVr}$ using the NeoChord procedure is a feasible alternative to conventional surgery for the subset of patients in the early stages of disease, when the lesions responsible for the mechanism of mitral regurgitation are limited to the mitral leaflets and/or chordae tendinae, including elongation or rupture, and do not include mitral annular or LV cavity dilatation. MVr with the NeoChord procedure has been shown to provide incremental benefit for the acute volumetric reduction of the left ventricle and atrium in this patient population, followed by the concomitant improvement in MV geometry immediately following trans-apical replacement of ruptured or elongated chordae with the NeoChord technology. These observations have been sustained in late follow-up periods (17-19).

In addition, in our series of patients, we have observed that the leaflet-to-annulus index (LAI) is helpful in predicting the amount of leaflet tissue that will yield post- 
procedure coaptation and significantly correlates with at most mild residual mitral regurgitation at one-year followup when the LAI is $>1.2$ (17). As recently reported, patients with a lower LAI (1.1 to 1.2) presenting with isolated central (P2) segment disease, might also undergo a successful $\mathrm{MVr}$ with the NeoChord procedure when associated with more anterior ventricular access (19-21). Ventricular access which is more anterior will modify the working angle of the posterior leaflet, stretching it below the anterior leaflet, and thereby increasing the potential leaflet coaptation. In patients with multi-segment posterior leaflet disease, special consideration must be given to the $\mathrm{LV}$ access site because of the potential for problematic interference between the native and placed artificial chords in the subvalvular apparatus. Of note, the proposed application of LAI may be restricted by regional anatomical limitations.

Finally, we have observed that MV morphology is a consideration affecting residual mitral regurgitation. As with conventional surgical $\mathrm{MVr}$, patients presenting with isolated central posterior leaflet prolapse or flail (type A morphology), as well as posterior multi-segment involvement (type B), demonstrate better outcomes than those patients with more complex MV lesions, such as anterior leaflet (type C) and paracommissural or calcified leaflets (type D) $(13,14,22,23)$. In our practice, patient selection criteria for $\mathrm{MVr}$ with the NeoChord procedure are well established and approximately $25-30 \%$ of patients presenting with degenerative mitral disease can be safely and effectively treated with the NeoChord procedure. In the future and with the rapidly expanding arena of catheter-based technologies for mitral repair, the combined application of multiple device therapies such as annuloplasty devices will increase the surgical armamentarium for MVr. There is potential for available strategies to be used synergistically with the NeoChord procedure, which may expand the pool of treatable patients to include those with more complex mitral pathology (24).

\section{Acknowledgements}

None.

\section{Footnote}

Conflicts of Interest: A Colli, G Gerosa received travel grants from Neochord, Inc. D Adams is the Co-Principal Investigator of the Rechord Trial, which is supported by Neochord, Inc. The other authors have no conflicts of interest to declare.

\section{References}

1. Baumgartner H, Falk V, Bax JJ, et al. 2017 ESC/ EACTS Guidelines for the management of valvular heart disease. Eur Heart J 2017;38:2739-91.

2. Perier P, Hohenberger W, Lakew F, et al. Toward a new paradigm for the reconstruction of posterior leaflet prolapse: midterm results of the "respect rather than resect" approach. Ann Thorac Surg 2008;86:718-25; discussion 718-25.

3. Seeburger J, Rinaldi M, Nielsen SL, et al. Off-pump transapical implantation of artificial neo-chordae to correct mitral regurgitation: the TACT Trial (Transapical Artificial Chordae Tendinae) proof of concept. J Am Coll Cardiol 2014;63:914-9.

4. Rucinskas K, Janusauskas V, Zakarkaite D, et al. Offpump transapical implantation of artificial chordae to correct mitral regurgitation: early results of a single-center experience. J Thorac Cardiovasc Surg 2014;147:95-9.

5. Colli A, Manzan E, Fabio FZ, et al. TEE-guided transapical beating-heart neochord implantation in mitral regurgitation. JACC Cardiovasc Imaging 2014;7:322-3.

6. Colli A, Zucchetta F, Torregrossa G, et al. Transapical off-pump mitral valve repair with Neochord Implantation (TOP-MINI): step-by-step guide. Ann Cardiothorac Surg 2015;4:295-7.

7. Colli A, Besola L, Gerosa G. Transapical Off-pump Neochord Implantation for Mitral Regurgitation Recurrence. Rev Esp Cardiol (Engl Ed) 2016;69:515.

8. Colli A, Bizzotto E, Pittarello D, Gerosa G. Beating heart mitral valve repair with neochordae implantation: real-time monitoring of haemodynamic recovery. Eur J Cardiothorac Surg 2017;52:991-2.

9. Colli A, Zucchetta F, Kliger C, et al. CT for the Transapical Off-Pump Mitral Valve Repair With Neochord Implantation Procedure. JACC Cardiovasc Imaging 2017;10:1397-400.

10. Seeburger J, Borger MA, Tschernich H, et al. Transapical beating heart mitral valve repair. Circ Cardiovasc Interv 2010;3:611-2.

11. Colli A, Manzan E, Aidietis A, et al. An early European experience with transapical off-pump mitral valve repair with NeoChord implantation. Eur J Cardiothorac Surg 2018;54:460-6.

12. Colli A, Bagozzi L, Banchelli F, et al. Learning curve analysis of transapical NeoChord mitral valve repair. 
Eur J Cardiothorac Surg 2018;54:273-80.

13. Colli A, Bellu R, Pittarello D, et al. Transapical offpump Neochord implantation on bileaflet prolapse to treat severe mitral regurgitation. Interact Cardiovasc Thorac Surg 2015;21:554-6.

14. Colli A, Manzan E, Rucinskas K, et al. Acute safety and efficacy of the NeoChord proceduret. Interact Cardiovasc Thorac Surg 2015;20:575-80; discussion 580-1.

15. Holzhey DM, Seeburger J, Misfeld M, et al. Learning minimally invasive mitral valve surgery: a cumulative sum sequential probability analysis of 3895 operations from a single high-volume center. Circulation 2013;128:483-91.

16. Murzi M, Cerillo AG, Bevilacqua S, et al. Enhancing departmental quality control in minimally invasive mitral valve surgery: a single-institution experience. Eur J Cardiothorac Surg 2012;42:500-6.

17. Colli A, Besola L, Montagner M, et al. Acute intraoperative echocardiographic changes after transapical off-pump mitral valve repair with NeoChord implantation. Int J Cardiol. 2018;257:230-4.

18. Kiefer P, Meier S, Noack T, et al. Good 5-Year Durability of Transapical Beating Heart Off-Pump Mitral Valve Repair With Neochordae. Ann Thorac Surg 2018;106:440-5.

19. Colli A, Besola L, Montagner M, et al. Prognostic

Cite this article as: Colli A, Adams D, Fiocco A, Pradegan N, Longinotti L, Nadali M, Pandis D, Gerosa G. Transapical NeoChord mitral valve repair. Ann Cardiothorac Surg 2018;7(6):812-820. doi: 10.21037/acs.2018.11.04 impact of leaflet-to-annulus index in patients treated with transapical off-pump echo-guided mitral valve repair with NeoChord implantation. Int J Cardiol 2018;257:235-237.

20. Colli A, Bizzotto E, Manzan E, et al. Patient-Specific Ventricular Access Site Selection for the NeoChord Mitral Valve Repair Procedure. Ann Thorac Surg 2017;104:e199-202.

21. Colli A, Manzan E, Zucchetta F, et al. Feasibility of anterior mitral leaflet flail repair with transapical beating-heart neochord implantation. JACC Cardiovasc Interv 2014;7:1320-1.

22. Colli A, Manzan E, Zucchetta F, et al. Transapical offpump mitral valve repair with Neochord implantation: Early clinical results. Int J Cardiol 2016;204:23-8.

23. Colli A, Manzan E, Besola L, et al. One-Year Outcomes After Transapical Echocardiography-Guided Mitral Valve Repair. Circulation 2018;138:843-5.

24. von Bardeleben RS, Colli A, Schulz E, et al. First in human transcatheter COMBO mitral valve repair with direct ring annuloplasty and neochord leaflet implantation to treat degenerative mitral regurgitation: feasibility of the simultaneous toolbox concept guided by $3 \mathrm{D}$ echo and computed tomography fusion imaging. Eur Heart J 2018;39:1314-5. 